\title{
A GRAMATOLOGIA DA CRÍTICA CULTURAL
}

\section{THE GRAMMATOLOGY OF THE CULTURAL CRITICISM}

\author{
Carlos Magno Gomes ${ }^{1}$
}

RESUMO: Este artigo retoma a herança teórica de Derrida a partir da recepção de seus conceitos pela crítica cultural contemporânea. No primeiro momento, comentaremos a importância dos conceitos: différance, suplemento, arquivo e herança, entre outros, para entendermos a flexibilidade do modelo interpretativo proposto por Derrida. No segundo, analisaremos como Homi Bhabha, Stuart Hall e Silviano Santiago exploram tais categorias para produzir uma crítica de revisão e de produção de ações interventivas, levando em conta questões políticas como hibridismo, identidade e entre-lugar.

PALAVRAS-CHAVE: Estudos culturais. Pós-colonialismo. Jacques Derrida.

\begin{abstract}
This article revisits the theoretical legacy of Derrida from the reception of its concepts by the contemporary cultural criticism. At first, we will comment on the importance of différance, supplement, archive and heritage, among others, to understand the flexibility of the interpretative model proposed by Derrida. Secondly, we will analyze how Homi Bhabha, Stuart Hall e Silviano Santiago exploit such categories to produce a critical criticism and the production of interventional actions, taking into consideration political issues as identity and the third space, respectively.
\end{abstract}

KEYWORDS: Cultural Politics. Cultural Studies. Post-Colonialism. Jacques Derrida.

\footnotetext{
${ }^{1}$ Prof. Associado de Teoria Literária da UFS. Doutor em Literatura pela UnB (2004), com pós-doutorado em Estudos Literários pela UFMG (2013). E-mail: calmag@bol.com.br
} 


\section{A GRAMATOLOGIA DA CRÍTICA CULTURAL}

A desconstrução de Jacques Derrida nos surpreende pelo vigor que mantém e se renova a cada década. Seu glossário filosófico está sempre sendo reutilizado e incorporado em diferentes métodos de pesquisa. Tal capacidade pode ser comprovada pela vitalidade e flexibilidade de um dos seus conceitos centrais - différance, que parte da ideia de "adiamento" do significante para explorar sua extensão. A différance expõe a quebra de paradigmas e abre a linguagem para seus mistérios, pois está vinculada à "desaparição da presença originária", sendo, portanto, "ao mesmo tempo, a condição de possibilidade e a condição de impossibilidade da verdade" (DERRIDA, 1997, p.121). Ao propor o "adiamento" do significante e a "impossibilidade da verdade", Derrida construiu um método de interpretação que rasurou os velhos conceitos da filosofia ocidental para descentrar os padrões impostos, colocando em cheque conceitos como universalidade, cânone, centro, autoria, entre outros, próprios das ciências humanas.

Ao propor tais rachaduras do significante no processo de interpretação, Derrida deixou aberto novos caminhos teóricos para a renovação da crítica cultural. Stuart Hall está entre os que exploram tais conceitos para quebrar paradigmas. Seus estudos sobre identidade e diferença são pautados pela différance, que abre a significação dos signos para decodificações diversificadas conforme os interesses ideológicos em jogo. Além disso, Hall explora, com propriedade, o conceito de rasura que atravessa os polos de uma identidade para expor os mecanismos que estão em jogo no processo de pertencimento. Ele justifica tal concepção pelo fato de os elementos das oposições identitárias estarem sempre rasurados um pelo outro, logo, não há uma identidade original, nem absoluta. O termo rasurado é usado pela valorização do "pensando no intervalo" dos conceitos tradicionais, vistos de forma destotalizados e desconstruídos (HALL, 2000, p.104).

Na mesma direção, Homi Bhabha retoma os movimentos da différance para construir o sofisticado conceito de "terceiro espaço", que é marcado pelo hibridismo e pelo posicionamento crítico do intelectual que passa a questionar as versões impostas pelos dominadores. Por uma perspectiva pós-colonial, a revisão do passado histórico é fundamental para a construção da crítica cultural, já que põe na berlinda a supremacia do colonizador diante das culturas colonizadas. Nesse caminho, Bhabha prega a valorização da produção do 
conhecimento a partir de uma postura de inquietude e de revisão que transforma o presente em um lugar de experiência e aquisição de poder (1998, p.23).

Dentro dessa tradição crítica, mas em solo brasileiro, Silviano Santiago ganhou destaque ao ressaltar o "entre-lugar" como uma opção crítica de revisão do passado. Ele é tido como divulgador do pensamento de Derrida desde a organização do Glossário de Derrida (1976). Santiago formula uma proposta de intervenção crítica a partir do projeto antropofágico do modernismo brasileiro. Seu consagrado ensaio "O entre-lugar do discurso latino-americano" nos convida a explorar o jogo que o conceito de différance traz a tona, questionando a dependência cultural. Com isso, Silviano Santiago propõe uma crítica cultural marcada pela antropofagia e pelo exercício do jogo para romper com a tradição. Com "o entre-lugar" do autor latino-americano, ele destaca que o crítico deve se preparar para questionar a tradição e buscar uma resposta ao processo de colonização, opondo-se ao processo de recepção passiva (2000, p.19).

Portanto, Bhabha, Hall e Santiago, ao se projetarem como críticos culturais influentes da contemporaneidade exploram o legado do filósofo francês para além do campo linguístico-filosófico, pois sua herança fillosófica pode ser usada de forma politizada e contextualizada para a revisão de conceitos e procedimentos investigativos de interpretação de dados e de interpretação de textos. Essa perspectiva nos convida a retornar a alguns de conceitos-chave do pensando de Derrida, que foram incorporados pela crítica cultural para a construção de uma agenda política preocupada em revisar e traduzir os sistemas de opressão.

Com tal objetivo, neste artigo, daremos ênfase às abordagens de Stuart Hall, Homi Bhabha e Silviano Santiago como modelos de estratégias de leitura que não só revisam o passado como também proporcionam modelos interventivos no presente. Do glossário de Derrida, além do conceito central de différance, exploraremos a capacidade de disseminação do termo phármakon como: parricídio, traição, envenenamento, silêncio, repetição, circularidade, entre outros. Esses significantes fazem parte do jogo da linguagem, e reforçam a flexibilidade do phármakon que inclui tanto remédio quanto veneno e traduz a ambivalência da modernidade. Com isso, queremos ressaltar a metodologia proposta de Jacques Derrida que, ao reler seus textos preferidos, constrói novas significações para conceitos cristalizados, visto que sua leitura é um processo transformador de textos que "desafiam o leitor a se desdobrar, a inventar ele próprio estratégias na medida da "leitura intensiva" (NASCIMENTO, 2001, p.20).

Para ressaltar o processo de atualização do pensamento de Derrida, exploraremos a relação entre o dentro e fora dos significantes por meio dos conceitos: suplemento, rastro, fantasma e arquivo, relacionando-os às estratégias discursivas para descentrar categorias do horizonte cultural de um povo. Vale destacar que Derrida explora o descentramento e o questionamento da tradição por meio de leitura/tradução do fonocentrismo. ${ }^{2}$ Assim, nesse método, tais conceitos têm a faceta de serem flexíveis e se adaptam a diferentes contextos e interesses políticos. Ao compor um glossário com uma vitalidade tão próspera, Derrida disponibilizou uma forma de pensamento que está sempre se adaptando e se renovando conforme as estratégias de uso. O pensador francês reconhece que sua proposta de "desconstrução" nasce de uma herança que não podia ser adiada no final dos anos 60 , quando o estruturalismo dominava a cena científica, pois se acha herdeiro desse pensamento, por isso buscou "responder por uma herança, num momento da história em que grandes obras já estavam elaboradas e presentes no campo da filosofia" (DERRIDA, 2004, p.15).

Evando Nascimento, estudioso e divulgador da obra de Derrida no Brasil, tem se voltado para analisar as fronteiras entre literatura e filosofia e propõe um modelo de leitura

\footnotetext{
${ }^{2}$ Derrida observa que tanto Saussure quanto os estruturalistas (Lévi-Strauss) operam com um conceito coloquial de escrita, puramente gráfica ou como um auxílio para a memória, por isso Derrida esforça-se por mostrar que essa distinção é insustentável, pois não há fronteiras tão nítidas entre a escrita e a fala. (LECHTE, 2002, p.126).
} 
que seguiremos neste artigo: o ler a partir de Derrida. Em seu estudo, Nascimento destaca as aproximações entre leitura e escrita na proposta filosófica de Derrida: "toda leitura é desde sempre repetição, reinstauração de um texto em face de outro que o precede, e esse outro se colocando numa sequência ou numa rede de outros textos ainda mais "originais"" (NASCIMENTO, 2001, p.20). Esse movimento da leitura, que é também de uma reescrita, dá sustentação a uma crítica cultural preocupada em atualizar os sentidos dos textos e dos arquivos coletivos e pessoais. Na sequência, comentaremos algumas de categorias centrais do pensamento de Derrida que foram explorados pelos críticos culturais em destaque.

\section{CATEGORIAS FUNDADORAS}

A crítica cultural se renova quando parte da concepção da desconstrução como uma herança metodológica. Sua vitalidade está na quebra da lógica fonocêntrica, alcançada pela exploração do jogo da linguagem e suas ambiguidades, quebrando os binarismos próprios do logocentrismo. Na cena central desse pensamento, estão a différance e o phármakon por estarem associados à dissimulação da escrita, que é marcada por um ato de traição em sua origem. Para construir seu argumento, Derrida retoma o pensamento de Platão, declarando que a traição é inerente ao ato da escrita, que não passa de um filho sem a presença do pai. Com esse reconhecimento, Derrida conclui que a escrita é "um filho desviado e revoltado, uma desmedida e uma perversão!", isto é, “um filho abandonado por seu pai. De qualquer modo, um filho perdido" (1997, p.97). Ao quebrar a vidraça da transparência da escrita, Derrida abre os significantes para diversos movimentos de interpretação. Tais movimentos se direcionam para fora da tradição, acrescentando a desconfiança e a fragmentação como estratégias acadêmicas opostas à lógica racionalista.

A postura desconstrutora do pensamento de Derrida recusa o logocentrismo como verdade absoluta e nos convida a pensar em diferentes sentidos que a linguagem apresenta-se como "jogo da representação", no qual a "origem torna-se inalcançável" (DERRIDA, 1999, p.44). Além disso, ele vai adiante e institui a quebra do binarismo entre o significante e o significado, reconhecendo que "o movimento do rastro é necessariamente ocultado, produz-se como ocultação de si” (DERRIDA, 1999, p.57). Portanto, em suas palavras, jogo e rastro são indispensáveis para a quebra da lógica racional. Além disso, Derrida problematiza a relação do signo com seu referente ou com o que está fora dele, visto que o rastro se opõe à lógica do retorno a uma origem simples e plena (NASCIMENTO, 2001, p.142). Ao quebrar a lógica do retorno, a desconstrução de Derrida libertou o pensamento ocidental da lógica racionalista, expondo uma fratura dessa concepção logocêntrica.

$\mathrm{O}$ ato de enunciação e a ambivalência da linguagem passam a ser analisados como constituidor de sentidos. Logo, a proposta de manutenção do mesmo plano interpretativo da tradição foi por água abaixo, visto que a ambiguidade da linguagem possibilita a invasão dos traços narrados, relevando a fragilidade da verdade e o movimento da circularidade dos seus sentidos. Nesse rumo, Derrida propõe uma investida nos suplementos da traição que a linguagem carrega, sem ter a certeza das convicções anteriores, reconhecendo que o traço é simultaneamente e inseparavelmente inscrição e intervalo, resíduo e diferença (JOHNSON, 2001, p.39). Tais conceitos são fundamentais para um crítico cultural que operacionalize suas interpretações a partir da investigação do silêncio dos excluídos, visto que, ao explorar a gramatologia de Derrida, está em jogo um método interpretativo para além das fronteiras do texto.

Outra pista que seguimos é a da força do conceito suplemento, considerado como um "terceiro estágio" do pensamento, que pode ser usado "tanto para completar os antecedentes quanto para superá-los e avançar em direção a algo diverso" (JAMESON, 2001, p.80). Dessa forma, a metodologia de Derrida inclui a leitura do suplemento da linguagem, deixando em 
aberto às diversas fendas e expondo os rastros que remetem um significante a outro, formando a cadeia de remessas constantes de significante em significante, pois "nunca houve senão suplementos, significações substitutivas que só puderam surgir numa cadeia de remessas diferenciais, o 'real' só sobrevindo, só acrescentando-se ao adquirir sentido a partir de um rastro e de um apelo de suplemento etc." (DERRIDA, 1999, p.194-195).

Para um glossário politizado da crítica cultural, a noção de suplemento é fundamental, pois está sempre propondo uma janela aberta para onde o crítico pode guiar seu olhar investigativo. Por meio do suplemento, podemos abrir o horizonte de expectativa de uma comunidade interpretativa e acrescentar novos significados para a cadeia de sentidos normatizados para aquele contexto. Tal estratégia é possível para as questões de identidade, raça e etnia, como ressaltado nos estudos de Bhabha e Hall. Na proposta de Derrida, o suplemento surge em um sistema de remessas diferenciais, pois acompanha a perspectiva da duplicidade do significante, visto que pode ser excesso ou adição necessária (LECHTE, 2002, p.126).

No campo da crítica cultural, a exploração da carga suplementar faz parte de uma estratégia de questionamento da tradição. No jogo do dentro e do fora do texto, o suplemento pode contaminar o texto, e abri-lo para sua exterioridade. Isso porque o externo é um signo, e como tal é um "representante [que] representa, sem dúvida, a alteridade do mal que vem afetar e infectar o dentro, irrompendo nele imprevisivelmente" (DERRIDA, 1997, p.80). Ora, ao trilhar a ponte entre o dentro e o fora, Derrida abriu o texto para seu contexto, possibilitando movimentos interpretativos para além do jogo textual. Além do mais, a proposta de Derrida abre espaço para a pulsão do mal que irrompe dentro do significante.

Ao reconhecer que o mal "afeta e infecta o dentro", Derrida abriu seu glossário para outras estratégias interpretativas, ressaltando, assim, o ato de enunciação. Essa perspectiva foi melhor elaborada em Espectros de Marx, obra que retoma a tradição marxista para comentar a coleção de fantasmas que rondam a humanidade. Em uma abordagem histórica, Derrida ressalta que somos herdeiros de nossas tradições e que essa questão não pode ficar de fora do processo de interpretação, pois testemunhamos à medida que herdamos, por meio de um processo circular, pois "herdamos isto mesmo que nos permite dar testemunho" (DERRIDA, 1994, p. 79). Nesse processo, as releituras não podem ser inocentes, uma vez que o espírito do povo sugere que há sempre uma aparição-sobrevivente que obedece à temporalidade do seu retorno (DERRIDA, 1994, p.196).

A questão coletiva, dessa forma, pode ser vista como um suplemento da crítica cultura contemporânea a partir da proposta de Derrida. Ao reconhecermos o povo como suplemento de um texto, identificamos uma mancha cega no texto, o não-visto que abre e limita a visibilidade (DERRIDA, 1999, p.200). Essa máscara da linguagem pode ser vista como um fantasma, ou uma cegueira programada, pois não conseguimos nos livrar dessa herança classificada como "efeito de viseira", que acontece quando não se vê quem olha, um alguém como algum outro, ego, sujeito, pessoa, consciência, espírito (DERRIDA, 1994, p.22). Esse "efeito de viseira" pode ser considerado como parte do protocolo de um crítico cultural, que não pode deixar que esse suplemento seja esquecido no processo de interpretação do texto. Nesses termos, a herança cultural não pode ficar de fora do raio de ação de um crítico preocupado em entender os fenômenos sociais atuais. Essa questão foi retomada no debate sobre a exterioridade do arquivo a partir de uma leitura de Freud em $O$ mal do arquivo. No tópico seguinte, exploraremos os rastros do arquivo coletivo como uma via politizada para uma tradução do ato da enunciação. 


\section{OS DESAFIOS DO ARQUIVO SOCIAL}

Retomando a ideia de suplemento, passemos a comentar a importância do conceito de arquivo para a crítica cultural politizada. $O$ arquivo visto aqui como uma herança, implicando "uma filtragem, uma escolha, uma estratégia" (DERRIDA, 2004, p.17). Lembramos que o arquivo é um espaço de enunciação ambíguo. Ao mesmo tempo em que tem uma concepção domiciliar, que sustenta seu valor, ele não consegue subtrair a violência que o produziu, posto que não esconde a opressão, nem o fato de nascer da "obtenção consensual de domicílio" (DERRIDA, 2001, p.13). Nesse duplo movimento de domicílio e de ruínas, o conceito de arquivo passou a ser usado pela crítica cultural politizada e preocupada em rever os símbolos da ocidentalização.

Por ser um texto posterior ao período de auge teórico, $O$ mal do arquivo traz uma releitura de conceitos-chave de sua gramatologia. Por exemplo, os movimentos que um arquivo esconde e releva, já está no cerne da gramatologia. Todavia, nesse texto, a sofisticação está no diálogo próximo com a teoria psicanalítica. Para o crítico cultural importa menos essa preocupação teórica, pois ao explicitar a exterioridade que o arquivo guarda, Derrida retoma, de forma metafórica, a barbárie da modernização. Seguindo esse raciocínio, os conceitos herança e testemunho aproximam-se de arquivo e espectro, explicitando a força do pensamento de Derrida em questionar os contextos sociais.

Portanto, ao trabalhar com o mal de arquivo, Derrida retoma as ideias de herança e de luto que fazem parte dos arquivos históricos. Grosso modo, o luto é uma herança coletiva e o arquivo vai testemunhar esse luto "somos herdeiros, e herdeiros enlutados, como todos os herdeiros" (DERRIDA, 1994, p.78). Isso porque o mal de arquivo está em sua constituição, sua relação com o dentro e o fora, posto que o princípio do arquivo "capitaliza tudo, incluindo aquilo que o arruína ou contesta radicalmente seu poder" (DERRIDA, 2001, p.24). Tal concepção não pode ficar de fora do ato interpretativo, pois pode produzir novas interpretações do passado, visto que os arquivos são contaminados por suas ruínas.

Nesse duplo movimento, a gramatologia de Derrida se revigora e dá sustentação a novas agendas interpretativas. O arquivo carrega seus suplementos e seus rastros e não pode ser mais lido apenas como uma fonte histórica hegemônica. Por isso, o "mal de arquivo" coloca na mesma balança as ruínas do poder, contestando sua legitimidade (DERRIDA, 2001, p.24). Se para a crítica estruturalista, a força do pensamento de Derrida estava no jogo da narrativa, a manutenção de seus conceitos e a ampliação do campo de aplicação desses conceitos reforça que a durabilidade de seu pensamento está na quebra da lógica interna do signo. Ao expor as máscaras dos significantes por meio de um complexo glossário filosófíco, Derrida segue na contramão da lógica logocêntrica, abrindo os sentidos dos próprios arquivos teóricos.

Por este prisma, o conceito de arquivo nos convida a pensar a narrativa histórica e seus movimentos de exaltação e silenciamento dos vencedores e vencidos. Esse processo põe em questão o que estamos vendo, pois o arquivo volta para nos inquirir sobre nossas atitudes. Esse movimento de leitura para além do que estamos vendo é desafiador, pois nos tira da zona de conforto. Nesse sentido, Derrida nos convida a pensar a cultura sem inocência, pois precisamos encarar que ela deixa em suas ruínas o registro dos silenciados. Sua concepção filosófica nos sugere a buscar outros sentidos para a cultura para além da relação dicotômica entre o dentro e o fora. Nesse caso, a voz silenciada, que faz parte da carga suplementar, é um mal-estar do arquivo.

Com isso, o arquivo nos convida sempre a pensar em sua carga suplementar, em sua duplicidade, isto é, uma adição de um significante para substituir ou suprir uma falta, oferecendo o excesso do significado (SANTIAGO, 1976, p.88). A categoria arquivo também pode ser explorada tanto para ícones, símbolos, metáforas que compõem a identidade cultural 
de um povo como palavras, resíduos de imagens e sons, entre outros elementos que compõem uma narrativa coletiva. Nessa direção, o crítico cultural deve levar em conta que o arquivo é parte de um contexto e é "ao mesmo tempo instituidor e conservador. Revolucionário e tradicional” (DERRIDA, 2001, p.17).

Seguindo tal jogo de significantes, os arquivos culturais devem ser analisados a partir desse duplo movimento como revolucionário e como instituidor, visto que portam a força coletiva. Nesse caso, a categoria arquivo pode ser explorada para além da visão freudiana, pois ele é um mal social, isto é, uma herança coletiva de um povo. Ao explicitar o poder, seja do vencedor, seja do dominado, o arquivo esconde as ruínas do perdedor, ou do que ficou para trás. Esse duplo movimento deve ser priorizado no processo de enunciação para que a carga suplementar seja escavada. Assim, o momento de produção de sentido é fundamental para que novos valores sejam agregados ao arquivo instituído. Para o sucesso dessa operação interpretativa, não podemos esquecer a ambiguidade da linguagem, reconhecendo que um "sistema de significados culturais" não é autossuficiente, já que ele é um "ato da enunciação cultural" e, como tal, "é atravessado pela différance" (BHABHA, 1998, p.65).

Portanto, um arquivo deve ser tratado com todo seu poder e sua dissimulação. No processo de busca dos sentidos de um arquivo, suas propriedades não devem ser esquecidas, "no sentido físico, histórico ou ontológico; isto é, ao originário, ao primeiro, ao principal, ao primitivo, em suma, ao começo" (DERRIDA, 2001, p.12). Todavia, nos rastros de sua primitividade, o arquivo nos remete ao seu exterior e nos convida a pensar no fora. Nesse caso, o arquivo traz de volta para a cena da enunciação as forças sociais que o produziram, pois ele é consignação, repetição e exterioridade, não havendo arquivo sem seu exterior (DERRIDA, 2001, p.22). Tal concepção de arquivo é indispensável para uma agenda crítica preocupada com os desafios da interpretação cultural.

Além disso, ao explorar o conceito de arquivo, o crítico cultural abre espaço para a politização da enunciação quando resolve enfrentar os fantasmas que rondam o arquivo. Mesmo sendo um processo que nos remete ao luto, não podemos abrir mão dessa herança que todo arquivo nos traz: "a herança não é jamais dada, é sempre uma tarefa. Permanece diante de nós, tão incontestavelmente que, antes mesmo de querê-la ou recusá-la, somos herdeiros" (DERRIDA, 1994, p.78). Para um crítico cultural, o luto faz parte de seu trabalho, pois é parte do arquivo. Logo, parte do ato de enunciação. Lembramos aqui que o texto literário pode ser trabalhado como um arquivo e como tal ele perde suas particularidades estéticas para ganhar outras texturas no ato de enunciação.

Essa postura de enfretamento do texto literário como um arquivo já foi explorado pela gramatologia de Derrida. Tal lição foi reduplicada com a particularidade dos críticos culturais, que passaram a enfatizar o que estava fora do texto. Se para Derrida, o movimento do texto deu consistência para a construção de seu pensamento; para os críticos culturais o fora do texto passou a ser uma meta investigativa. Tal modificação é sustentada pelas reflexões heterogêneas dos estudos culturais que não se remetem a uma origem única, já que comporta múltiplos discursos e diferentes histórias em conflito. Dentro dessa estratégia de leitura, o crítico cultural valoriza as questões sociais para destotalizar as interpretações historicamente construídas com a finalidade de se libertar de horizontes interpretativos impostos.

Dentro dessa tradição, da escavação dos sentidos dos arquivos, destacamos o modelo de crítica cultural desenvolvido por Hall, Bhabha e Santiago. Esses críticos, em diferentes contextos, colocam em tensão o conceito de identidade ao reconhecer sua exterioridade, isto é, a alteridade. Tal modelo crítico incorpora diferentes abordagens sobre política, póscolonialismo, sexualidade e questões etnicorraciais, ampliando a agenda de debate e passando a valorizar o lugar das identidades em diferentes manifestações artísticas e culturais 
(RESENDE, 2005, p.256). A seguir, veremos que esses críticos atualizaram o glossário de Derrida ao incorporar questões políticas aos seus conceitos fundadores.

\section{A CRÍTICA CULTURAL POLITIZADA}

Neste tópico, comentaremos como a herança de Derrida foi filtrada pelos estudos culturais e pelos estudos pós-coloniais, levando em conta que é preciso avançar para além da contradição formal e aparente, "entre a passividade da recepção e a decisão de dizer 'sim', depois solicitar, filtrar, interpretar" por meio de um processo que trabalha a herança de uma "dupla injunção contraditória e desconfortável” (DERRIDA, 2004, p.13). Nessa direção, vamos comentar como alguns conceitos foram recepcionados e interpretados pela crítica cultural. Conscientes da capacidade de renovação desses, Bhabha e Hall contribuíram para o desenvolvimento de uma crítica cultural interventiva e compromissada com os problemas políticos do mundo contemporâneo. Por exemplo, Bhabha explora a cadeia de suplementos das palavras, com seus sentidos em expansão, ao propor um processo de interpretação que vai além das lacunas históricas, pois ele está preocupado com a "tradução social" e a produção de um espaço, que não é apenas o corte ou lacuna do sujeito, mas também a interseção de lugares e disciplinas sociais $(1998, \mathrm{p}, 103)$.

Dentro dos estudos sobre a cultura, a différance emerge como um conceito básico que nos remete às fronteiras e às margens sociais. Tais especificidades fazem parte do método de abordagem de Hall, por exemplo, quando ressalta que a identidade fixa é uma miragem, visto que sua construção "opera por meio da différance, ela envolve um trabalho discursivo, o fechamento e a marcação de fronteiras simbólicas, a produção de "efeitos de fronteiras"” (HALL, 2000, p.106). Assim, segundo o pensamento do jamaicano, tanto a identificação como o que está fora dessa escolha fazem parte do processo da construção de uma identidade.

Além de explorar o conceito de différance, a perspectiva teórica de Hall retoma a fragmentação da ideia de centro, visto que não há mais um centro fixo, posto que a totalidade está fora de qualquer centro. Nessa lógica, esse crítico cultural explora a flexibilidade da linguagem como parte de seu método de análise, quando articula as identificações sociais como não harmoniosas, por isso reforça seu "conceito estratégico e posicional" para o estudo da identidade, já que esse conceito "não assinala o núcleo estável do eu que passa, do início ao fim, sem qualquer mudança, por todas as vicissitudes da história" (2000, p.108).

Se Hall explorou o conceito de différance para deixar para trás a uniformidade e unidade da identidade, Bhabha retoma esse conceito para ressaltar que não há uma cultura uniforme. Ele explora o conceito de metáfora para mergulhar no tecido cultural como uma textura híbrida e coletiva. Assim, ao reconhecer que as metáforas culturais acumulam posições discursivas contraditórias, Bhabha amplia os sentidos da crítica cultural, visto que "a metáfora produz realidades híbridas pela junção das tradições de pensamento totalmente distintas" (1996, p.37).

Assim, ao mesmo tempo em que reconhecem a fronteira como um território de troca de experiências, tanto Bhabha quanto Hall abrem caminho para a inclusão da diferença e da alteridade como partes indissociáveis da crítica cultural. Nesse caso, o processo de identificação é perturbador, visto que "é apenas por meio da relação com o Outro, da relação com aquilo que não é, com precisamente aquilo que falta, com aquilo que tem sido chamado de seu exterior constitutivo, que o significado positivo de qualquer termo pode ser construído" (HALL, 2000, p.110). Entre o sujeito e a alteridade, há uma intersecção, que não é simples, nem fixa, gerando novos sentidos para o crítico, pois se trata de "um processo de se identificar com e através de outro objeto, um objeto de alteridade, ponto no qual a ação de identificação - o sujeito - é ela mesma sempre ambivalente, por causa da intervenção dessa alteridade" (BHABHA, 1996, p.37). 
Levando em conta tal premissa, constatamos que ao explorar esses conceitos de forma coerente com uma proposta política, esses dois teóricos ressaltam o quanto a gramatologia da desconstrução se fortalece em contato com as tensões sociais. Dentro dessa perspectiva, o crítico cultural deve ser capaz de reconhecer as diferentes tensões e discursos que compõem uma identidade cultural. Essa construção não é simples e nem é mantida apenas pelas normas legitimadoras, pois há momentos de negociação e de desconforto. Essa perspectiva leva em conta o próprio conceito de linguagem formulado por Derrida, posto que "não há significado que escape, mais cedo ou mais tarde, ao jogo das remessas significantes, que constitui a linguagem. O advento da escritura é o advento do jogo" (DERRIDA, 1999, p.8). Tal ambivalência estende-se por um número maior de conceitos e nos possibilita a construção de uma teoria crítica que também investigue o quanto esse termo pode ser explorado como sedução, envenenamento, droga, antídoto etc. (NASCIMENTO, 2001, p.116).

Diante da dinâmica do pensamento de Derrida, cabe ao crítico cultural explorar metodologicamente seus conceitos conforme os interesses em jogo, já que o jogo de sentidos e valores que sustenta a legitimidade da linguagem depende das estratégias de tradução de seus usos, sentidos e apropriações. Como a identidade cultural é híbrida e de fronteiras, uma estratégia que não pode faltar ao crítico cultural é explorar as oposições em jogo de forma rasurada. Para isso, é necessário incluir partes envolvidas no processo de formação dessa cultura como identidade, diferença e alteridade. Pensar sob rasura, significa reconhecer que há posições discursivas de intersecção e posições que questionam velhas fórmulas: "no intervalo entre a inversão e a emergência: uma ideia que não pode ser pensada da forma antiga, mas sem a qual certas questões-chave não podem ser sequer pensadas" (HALL, 2000, p.104).

Levando em conta tal intersecção, podemos constatar que o vigor da gramatologia de Derrida está na forma como a enunciação é interpretada pelo crítico cultural. Para uma agenda política de revisão, o espaço da enunciação torna-se um local de implosão da pacífica diversidade cultural para construir estratégia que reconhece a ambivalência da linguagem, visto que "o conhecimento cultural é em geral revelado como código integrado, aberto em expansão" (BHABHA, 1998, p.67). Tal processo de ressignificação parte da abertura das narrativas para a identificação do "com" e do "através" do outro representado no texto, isto é, "um objeto de alteridade, ponto no qual a ação de identificação - o sujeito - é ela mesma sempre ambivalente, por causa da intervenção dessa alteridade" (BHABHA, 1996, p.37).

Tal perspectiva, influenciada pelas teorias culturais, com suas dúvidas e questionamentos, colocou em pauta o hegemônico, valorizando a hibridização como uma estratégia ideológica. A fragmentação e a fratura das identidades passam a fazer parte da identidade cultural em oposição a um 'eu' coletivo do pertencimento identitário que é construído de forma múltipla "ao longo dos discursos, práticas e posições que podem se cruzar ou ser antagônicas" (HALL, 2000, p.108). Com esse reconhecimento, a atualização do enunciado passa pela valorização de se pensar no intervalo dos conceitos tradicionais. Esse pensar a partir das interseções é próprio do hibridismo como uma estratégia para desestabilização das construções sígnicas, trazendo para o "tempo das culturas" outras formas de representação, outras comunidades, numa conexão intercultural (BHABHA, 2011, p.91).

A partir da interculturalidade, a descrença em conceitos como unidade e centro passa a ser uma referência para uso do rastro como metodologia de investigação. O rastro não é somente a desaparição da origem, mas a confirmação que a origem jamais foi reconstruída a não ser por uma não origem, visto que o rastro, que se torna, assim, a origem da origem (DERRIDA, 1999, p.75). Nesse processo, em que não há obrigatoriedade de se seguir uma origem, o crítico cultural tem se guiado por questões políticas e ideológicas, para teoricamente "destotalizar" as interpretações historicamente impostas para retomá-las "dentro 
de um referencial alternativo" (HALL, 2003, p.402). Essa alternativa passa pelas fronteiras culturais que apresentam diversas identidades e significados com suas heranças, males e fantasmas. Seguindo esses movimentos fronteiriços, a crítica cultural pode ser considerada uma herdeira de Derrida. Esse processo não é de simples repetição, mas de interpretação, pois "um herdeiro não é apenas alguém que recebe, é alguém que escolhe, e que se empenha em decidir" (DERRIDA, 2004, p.17).

\section{A HERANÇA BRASILEIRA}

No Brasil, Silviano Santiago foi um dos pioneiros na divulgação da obra do filósofo francês. Em Glossário de Derrida (1976), obra organizada por Santiago, temos a tentativa de aproximação do público brasileiro com os conceitos centrais da obra de Derrida. Em seus depoimentos, Santiago destaca sua formação pós-estruturalista. Eneida Cunha reconhece esse vínculo teórico do brasileiro e ressalta sua preocupação com as questões sociais: "A arte política de Silviano Santiago tem dicção múltipla e escuta com atenção, como ele próprio declara, o espectro hamletiano" (2008, p.9).

No seu clássico ensaio sobre "O entre-lugar do escritor latino-americano", o crítico brasileiro ressalta o lugar do autor como de produção de conhecimento e de revisão do passado de um lugar de transgressão:

\footnotetext{
entre o sacrifício e o jogo, entre a prisão e a transgressão", entre a submissão ao código e a agressão, entre a obediência e a rebelião, entre a assimilação e a expressão, - ali, nesse lugar aparentemente vazio, seu templo e seu lugar de clandestinidade, ali se realiza o ritual antropófago da literatura latino-americana (SANTIAGO, 2000, p.26).
}

Ao articular o jogo como método de pesquisa, Santiago ressalta o quanto a linguagem não era tão precisa como pregada pela tradição. Nessa trilha, o crítico brasileiro abre espaço para a tradução da violência e da barbárie impostos pela colonização, atualizando os sentidos dos signos, símbolos, discursos, imagens, que deixaram os rastros da dominação cultural.

Em uma segunda etapa de seu pensamento crítico, o método de descentramento da tradição de Silviano Santiago consolida-se por sua postura de análise da cultura brasileira, em particular a literatura. Ele defende que nossa literatura tem uma tradição anfíbia, que é própria do contexto social que demanda uma postura política do escritor, que, ao mesmo tempo, incorpora conceitos estéticos importados. Tal recorrência assinala o caráter híbrido da forma literária brasileira, pois os "melhores livros apontam para a Arte, ao observar os princípios individualizantes, libertadores e rigorosos da vanguarda estética europeia, e ao mesmo tempo apontam para a Política" (SANTIAGO, 2004, p.66).

Tal postura política desse crítica já se encontra em seu ensaio sobre o papel do escritor latino-americano. Dentro da perspectiva política, Santiago aponta que América Latina é responsável pela "destruição sistemática dos conceitos de unidade e pureza" (SANTIAGO, 2000, p.16). Essa postura híbrida do escritor também vai se manifestar em grande parte dos críticos culturais brasileiros. Todavia, a diferença vai recair naqueles que conseguem fazer a revisão do passado e não apenas repetir os discursos hegemônicos que acontecem quando buscamos resgatar a represenção "dos miseráveis a fim de elevá-los à condição de seres humanos" (SANTIAGO, 2004, p.66).

Eneida Cunha ressalta a relação teórica e de postura ideológica entre os dois textos de Santiago. Em ambos, temos uma preocupação do crítico com o contexto social do escritor e seu envolvimento em fazer Arte e Política ao mesmo tempo. O "entre-lugar" abre espaço para um conceito mais elabora: "a "literatura anfíbia". Esse segundo "deve responder ao 
desafio da realidade socioeconômica e cultural brasileira, na qual o analfabetismo ou o escasso letramento de um segmento da população se casa com a força envolvente da mídia eletrônica" (CUNHA, 2008, p.8). Para Santiago um dos papeis do escritor é o de se aproximar do papel do intelectual, pois deve estar preocupado não só com sua arte, mas também em conquistar leitores. Em síntese, as reflexões teóricas de Santiago aproximam-se do pensamento antropofágico do modernismo que questionava a identidade cultural nacional como sorridente e carnavalesca, própria para férias e turismo cultural.

Nesse sentido, crítica literária e história cultural se confundem, pois exige uma análise detalhada do contexto da enunciação em jogo. A partir de tal perspectiva, a crítica se torna mais eficiente quando passa a ser exercida como uma prática inclusiva e de reconhecimento da alteridade e da diversidade nas representações culturais. Com esse movimento híbrido, por meio da identificação dos suplementos e dos rastros da opressão, o objeto analisado pode receber contornos próprios que melhor explore os dilemas da sociedade brasileira contemporânea.

Em Santiago, a herança de Derrida se manifesta não só pela exploração dos conceitos, mas pela postura consciente de fazer crítica a partir de seu lugar histórico. No caso brasileiro, tal postura tambem pode ser identificada na história literária, quando reconhecemos que o escritor brasileiro é atormentado pelo fantasma do povo, pois de um lado a arte é vista apenas como conhecimento do mundo, do outro como um exercício de crítica social e de busca de um governo democrático e justo (SANTIAGO, 2004, p.72).

Tal concepção híbrida da tradição literária no Brasil, retoma a ideia inicial do "entrelugar", ressaltando que "arte" e "política" não podem ser dissociada na prática do crítico cultural, visto que, por uma postura política, o crítico cultural não pode deixar de incluir em sua agenda a situação histórica das desigualdades sociais e deve avançar nas análises "da burguesia econômica nos seus desacertos e injustiças seculares" (SANTIAGO, 2004, p.66). Portanto, o modelo de desconstrução de Derrida encontra eco nas posturas críticas de Santiago que sempre pregou instigou a insubordinação e a mudança como tarefas inadiáveis para o escritor e o crítico brasileiro. Essa postura está presente não só nos textos teóricos, mas também em seus textos ficcionais.

Assim, com uma postura compromissada, Silviano Santiago destaca a necessidade de mudança nas políticas públicas e nos textos ficcionais com abertura de espaço para outras vozes historicamente silenciadas. Entre essas mudanaças, ele destaca que há urgência de protagonismo das mulheres e dos negros "nas relações e nos postos de poder" (CUNHA, 2008, p.9).

\section{CONSIDERAÇÕES FINAIS}

Retomando a reflexão sobre a crítica cultural, constatamos que a herança de Derrida foi explorada para além do jogo textual. A exploração da exterioridade do significante foi indispensável para que seu pensamento fosse incorporado pela crítica cultural que colocou a unidade da linguagem na berlinda. Essa postura contemporânea reforça o poder de revisão de sua gramatologia que também pode ser explorada na "problematização e politização do termo cultura" (RESENDE, 2005, p.248). Com o reconhecimento da importância do aspecto político, a ambiguidade da linguagem e a hibridez cultural não podem ser invisibilizadas por conceitos homogêneos.

Como uma herança que está sempre voltando, os conceitos de Derrida ajudam-nos a traduzir o passado sem perder a noção de que a linguagem não é transparente. Dessa lição, fica a consciência de que a linguagem também envenena, por isso traduzir é deslocante e traiçoeiro, uma vez que a essência do original não é reforçada e sim simulada, reproduzida, transferida, transformada, ou tornada um simulacro. Nunca o original se conclui ou se 
completa em si mesmo (BHABHA, 1996, p.36). Seguindo esse modelo de crítica, o referencial alternativo deve ser construído no processo de análise dos dados e interpretação dos fatos.

Tal postura crítica de retomada dos significados de um referencial alternativo passa também pela análise das diversas posições identitárias em jogo. Com isso, retomamos a herança de um pensamento baseado na diferença e no deslocamento de valores, que não deixa o sentido do texto parar, possibilitando uma disseminação dos seus significados. Como modelo dessa postura, destacamos o diálogo do pensamento de Hall, Bhabha e Santiago, que retomam o passado a partir de um novo referencial teórico para enfrentar e desarmar o conservadorismo e a tradição. Esses críticos culturais retomam a premissa derridiana de privilegiar o lugar de enunciação, reconhecendo que as representações culturais são entrecortadas por relações de poder, representações identitárias, histórias, que através do movimento crítico podem ser re-locadas e re-significadas (BHABHA, 2011, p.82-83).

Tal proposta se configura quando categorias da gramatologia são usadas com a intensão de avançar na interpretação dos conflitos sociais para fragmentar verdades, adequando-as ao horizonte cultural em jogo, visto que a linguagem é um ato de produção dos ícones, dos símbolos, dos mitos e metáforas por meio dos quais o homem vive sua própria cultura (BHABHA, 1996, p.36). Ao destacarmos o campo cultural e a provisoriedade de seus valores, reconhecemos que as dúvidas e questionamentos são indispensáveis para uma crítica preocupada com o "como" está sendo feita.

Tal preocupação é herdeira da desconstrução. Assim, ao priorizar a revisão histórica das representações culturais, a crítica cultural tem retomado a gramatologia de Derrida de um lugar renovador que agrega outras concepções políticas aos seus conceitos fundadores. Nesse sentido, o papel do crítico é de decodificar o passado, reconhecendo que a linguagem faz parte de um "processo contínuo de significação do mundo cultural e ideológico, que está sempre significando e ressignificando - esse processo é sem fim" (HALL, 2003, p.362). Como premissa indispensável para essa decodificação, a revisão deve questionar a democracia cultural e se opor à democracia racial, pois deve levar em conta que a "memória mítica" da "identidade coletiva única" é utópica (BHABHA, 1998, p.63).

Portanto, ao lermos a cultura a partir do pensamento de Derrida, estamos colocando em jogo, o próprio universo das representações culturais. Se, coletivamente, apresentamos diferentes pontos de vista, nada fica fora da ordem ao optarmos por desmascarar o conceito de cultura como um todo completo em si mesmo, abrimos o texto para os sentidos dos suplementos e rastros dos arquivos sociais.

Constatamos, sobretudo, que ao agregar valores políticos aos termos do glossário de Derrida, a crítica cultural alargou as fronteiras políticas e dinamizou a agenda de lutas do mundo contemporâneo. Hall, Bhabha e Santiago são exemplos de pensadores que se apropriaram de conceitos-chave do pensamento de Derrida para constuir uma agenda teórica sofisticada e dinâmica. Para eles, a crítica cultural deve investigar as tensões políticas, pois estamos reconhecendo que há "uma lógica da causalidade e da determinação através das quais reconhecemos o político como uma forma de cálculo e ação estratégica dedicada à transformação social" (BHABHA, 1998, p.48).

Com tais constatações, ratificamos que conceitos como différance, arquivo, suplemento, herança, entre outros, são fundamentais para uma agenda politizada do trabalho do crítico cultural contemporâneo, pois reforçam a ideia de hibridismo e de interseção que atravessam o tecido social. A incorporação de forma politizada desses termos proporcionou uma ampliação dos sentidos da gramatologia, inaugurando um espaço de negociação, que reconhece que o poder é desigual, e possibilita "um agenciamento 'intersticial', que recusa a representação binária do antagonismo social” (BHABHA, 2011, p.91). 


\section{REFERÊNCIAS}

BHABHA, Homi. O entre-lugar das culturas. In: BHABHA, Homi. O bazar global e o clube dos cavalheiros ingleses. Org. Eduardo Coutinho. Rio de Janeiro: Rocco, 2011.

BHABHA, Homi. O local da cultura. Trad. de Myriam Ávila et alli. Belo Horizonte: UFMG, 1998.

BHABHA, Homi. O terceiro espaço. Revista do Instituto do Patrimônio Histórico e Artístico Nacional, n.24. Entrevista concedida a Jonathan Rutherford, 1996.

CUNHA, Eneida Leal. Apresentação: Os entre-lugares de Silviano Santiago. In CUNHA, Eneida Leal. Leituras críticas sobre Silviano Santiago. Belo Horizonte: UFMG; São Paulo: Fundação Perseu Abramo, 2008, p. 07-21.

DERRIDA, Jacques. A farmácia de Platão. 2.ed. Trad. de Rogério Costa. São Paulo: Iluminuras, 1997.

DERRIDA, Jacques. Espectros de Marx. Trad. de Anamaria Skinner. Rio de Janerio: Relume - Dumará, 1994.

DERRIDA, Jacques. Gramatologia. 2.ed. Trad. de Miriam Chnaiderman e Renato J. Ribeiro. São Paulo: Perspectiva, 1999.

DERRIDA, Jacques. Mal de arquivo: uma impressão freudiana. Trad. De Claudia de Moraes Rego. Rio de Janeiro: Relume Dumará, 2001.

DERRIDA, Jacques. Escolher sua herança. Entrevista dada a Elisabeth Roudinesco. In DERRIDA, Jacques; Roudinesco. De que amanhã... diálogo. Rio de Janeiro: Jorge Zahar Editora, 2004, p. 09-31.

HALL, Stuart. Da diáspora - identidades e mediações culturais. Trad. de Adelaine La Gaurdia Resende et alli. Belo Horizonte, UFMG, 2003.

HALL, Stuart. Quem precisa da identidade? In SILVA, Tomaz Tadeu da (org.). Identidade e diferença. Petrópolis: Vozes, 2000.

JAMESON, Fredric. 'Fim da arte' ou 'fim da história'?. In JAMESON, Fredric. A cultura do dinheiro. Trad. de Maria Elisa Cevasco e Marcos César de Paula Soares. Petrópolis: Vozes, 2001.

JOHNSON, Christopher. Derrida. Trad. de Raul Fiker. São Paulo: Unesp, 2001.

LECHTE, John. 50 pensadores contemporâneos essenciais. Trad. de Fábio Fernandes. $2^{\mathrm{a}}$. ed. Rio de Janeiro: DIFEL, 2002.

NASCIMENTO, Evando. Derrida e a Literatura - "Notas" de literatura e filosofia nos textos da desconstrução. 2.ed. Niterói: EdUFF, 2001. 
SANTIAGO, Silviano. O entre-lugar do discurso latino-americano. In SANTIAGO, Silviano. Uma literatura nos trópicos. São Paulo: Companhia das Letras. 2000, p. 09-26.

SANTIAGO, Silviano (Superv.). Glossário de Derrida. Rio de Janeiro: Francisco Alves, 1976.

Recebido em: 03 de fevereiro de 2015.

Aceito em: 08 de julho de 2015. 